\title{
High-Performance Non-Fullerene Acceptor Derived from Diathiafulvalene Wings for Solution-Processed Organic Photovoltaics
}

\author{
Suman, ${ }^{\dagger, \ddagger}, \|$ Anirban Bagui, ${ }^{\dagger, \|}$ Vinay Gupta, ${ }^{*}, \S$ K.K. Maurya, ${ }^{\S}$ and Surya Prakash Singh ${ }^{*}, \dagger, \ddagger$ \\ ${ }^{\dagger}$ Inorganic and Physical Chemistry Division, CSIR-Indian Institute of Chemical Technology (IICT), Uppal Road, Tarnaka, \\ Hyderabad, 500007, India \\ ${ }^{\ddagger}$ Academy of Scientific and Innovative Research (AcSIR), New Delhi, India \\ ${ }^{\S}$ CSIR-National Physical Laboratory, Dr. K. S. Krishnan Marg, New Delhi, 110012, India
}

\section{Supporting Information}

ABSTRACT: A solution-processable small-molecule nonfullerene electron acceptor BAF-2HDT (7,7'-(9,9-didecyl-9H-fluorene-2,7-diyl)bis(4((4,5-bis(hexylthio)-1,3-dithiol-2 ylidene)methyl)benzo[c][1,2,5]thiadiazole) bearing hexadiathiafulvalene (HDT) wings as end groups has been synthesized for bulk heterojunction organic photovoltaics. The molecule shows broad absorption in the 300-600 $\mathrm{nm}$ range with a molar extinction coefficient $(\varepsilon)$ of $9.32 \times 10^{4} \mathrm{M}^{-1} \cdot \mathrm{cm}^{-1}$ exceeding to that of $[6,6]$-phenyl- $\mathrm{C}_{71}$-butyric acid methyl ester of $2.8 \times 10^{4} \mathrm{M}^{-1} \cdot \mathrm{cm}^{-1}$ at 461 $\mathrm{nm}$. The HOMO and LUMO energy levels of the molecule are found to be -5.69 and $-3.58 \mathrm{eV}$, respectively which is compatible with low band gap high-performance polymers such as poly[(5,6-difluoro-2,1,3-benzothiadiazol-4,7-diyl)-alt-(3,3'"-di(2-octyldodecyl)-2,2' $; 5^{\prime}, 2^{\prime \prime} ; 5^{\prime \prime}, 2^{\prime \prime \prime}$-quaterthiophen-5,5"'-diyl)] (PffBT4T-2OD). Photoluminescence-quenching measurements confirm that the molecule BAF-2HDT has excellent

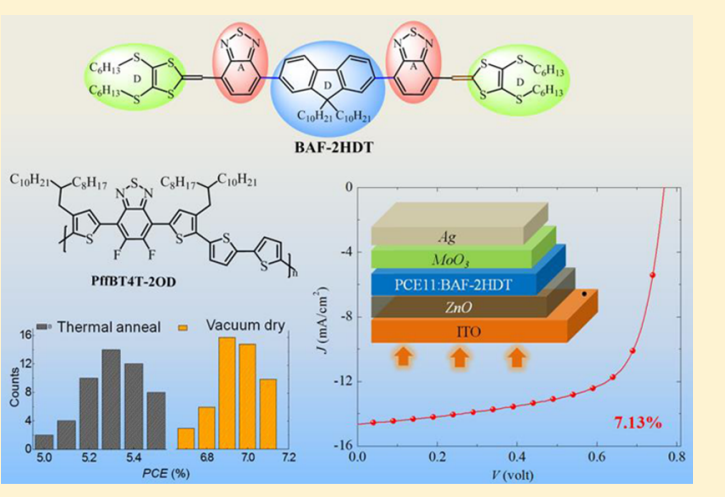
electron-accepting capability. The organic solar cells made from BAF-2HDT blending with conjugated polymer donor PffBT4T$2 \mathrm{OD}$ exhibit a power conversion efficiency of $7.13 \%$ with high $V_{\mathrm{oc}}$ of $0.77 \mathrm{~V}, J_{\mathrm{sc}}$ of $14.64 \mathrm{~mA} \cdot \mathrm{cm}^{-2}$, and FF of 0.64 . The design and development of such nonfullerene acceptors with high $\varepsilon$ may be key to further development of high-performance and costeffective solution-processed organic solar cells.

\section{INTRODUCTION}

Organic photovoltaics (OPV) offer several technological advantages over their inorganic counterparts such as low production cost and the possibility of fabricating lightweight and flexible devices via simple solution deposition techniques. ${ }^{1}$ Conjugated polymer-based organic solar cells (OSCs) achieved power conversion efficiencies (PCEs) over $10 \%$, a benchmark widely considered to be the threshold for commercialization. ${ }^{2}$ Design and development of conjugated polymer donors for OPV application has been an attractive research field during the past few decades. The interest is shifted toward the development of solution-processable high performance small molecule donor and acceptors for OPV application in past few years because the small organic molecules have certain advantages compared to conjugated polymers in making organic solar cells as they have definite molecular weight, higher degree of purity, and absence of batch-to-batch variation during production. ${ }^{3}$ High PCEs of $9-10 \%$ have been achieved in the case of solution-processed, small-molecule donor-based organic solar cells. ${ }^{4}$ However, in the case of acceptors, most of the research groups are mainly modifying fullerene and its derivative, $[6,6]$ -

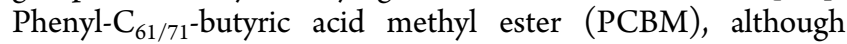
PCBM and other fullerene derivatives have limited absorption, wide band gaps, high synthetic costs, are difficult to purify, and exhibit limited open circuit voltage $\left(V_{\text {oc }}\right)$ in the case of OSCs made with those compounds. ${ }^{5-9}$ To overcome the aforesaid drawbacks, researchers recently started working on the development of nonfullerene acceptors (NFAs), which offers defined molecular structures, tunable absorbance and energy gaps, adjustable frontier molecular orbital energy levels, facile synthesis, low-cost production, and easy purifications. ${ }^{10-13}$

Some high-performance NFAs have been recently developed for OPV applications, and the BHJ organic solar cells fabricated with these molecules show high PCEs exceeding $11 \% .{ }^{14}$ The most common structural template involves small molecules containing electron-deficient units, viz., perylene diamides, ${ }^{2,15-20}$ diketopyrrolopyrrole, ${ }^{7,21,22}$ benzothiadiazole, rhodanine, $^{23-26}$ and dicyanovinyl. ${ }^{27-29}$ Although a significant advancement in this field occurred only in the last few years, the first ever bilayer OSC invented by Tang in 1986 was made from an NFA, named 3,4,9,10-perylenetetracarboxylic bisbenzimidazole (PTCBI), and small-molecule donor copper phthalocyanine $(\mathrm{CuPc})$ yielding a PCE of $1 \%{ }^{30}$ In the following years, photovoltaic performance of few other NFAs,

Received: August 2, 2016

Revised: September 30, 2016

Published: October 3, 2016 
e.g., 3-pentyl-substituted PDI ${ }^{31,32}$ and DPP-thiophene-2carbonitrile terminated alkylated fluorene (F8-DPPTCN), ${ }^{33}$ was reported. Ding et al. synthesized a series of NFAs from fluoranthene-fused imide (FFI), and the OPV devices constructed incorporating those molecules with donor poly(3-hexylthiophene-2,5-diyl) (P3HT) showed PCEs in the range of 2.11-2.9\%. ${ }^{34}$ Asymmetric electron acceptors based on fluorene, benzothiadiazole (BT), dicyanovinyl (DCV), and DCV-substituted quinarcidone were also developed by some research groups. ${ }^{28,35}$ Winzenberg et al. designed and synthesized an NFA-containing fluorene core with end-cap of indane1,3-dione and achieved PCE up to $2.43 \%$ when blended with P3HT. ${ }^{36}$ An NFA labeled as IDT-2BR bearing a benzothiadiazole rhodanine terminated indacenodithiphenithiophene unit was synthesized by Wu et al., and a PCE of $5.12 \%$ was reported from a P3HT:IDT-2BR-based solar cell. ${ }^{37}$ A perylene bisimide (PBI) dimer-based acceptor SdiPBI-S, developed by Sun et al., yielded a PCE of $7.16 \%$ comprising a wide band gap polymer PDBT-T1 as the electron donor. ${ }^{38}$ A high PCE of $9.6 \%$ was reported from a solar cell constructed with an efficient fusedring NFA named ITIC-Th based on an indacenodithieno[3,2b]-thiophene core and thienyl side chains. ${ }^{4}$

In this work, we have synthesized a small-molecule NFA BAF-2HDT (Figure 1) with a broad absorption range and a

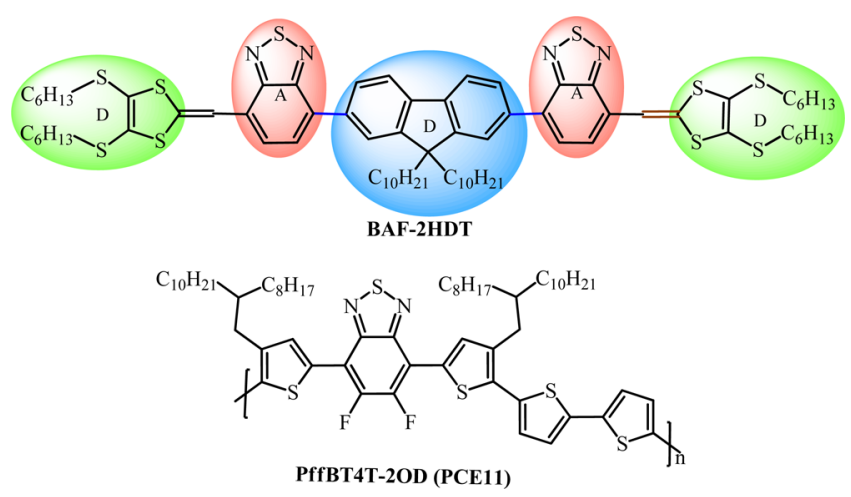

Figure 1. Molecular structures of newly developed NFA molecule BAF-2HDT and conjugated polymer donor PffBT4T-2OD used for the fabrication of $\mathrm{BHJ}$ solar cells.

very high $\varepsilon$ value having fluorene (a weak electron donating unit) as the core with arms of HDT-terminated benzothiadiazole (BT) (electron-withdrawing parts). Organic solar cells based on calamitic-type NFAs having an electron-rich moiety such as fluorene as a central core show better performance in comparison to those acceptors having an electron-deficient central unit like benzothiadiazole. This may be in part because typical electron-deficient units like benzothiadiazole have no position available for alkyl chains, and therefore, solubilizing groups must be located on the periphery of the molecule, making the lowest unoccupied molecular orbital (LUMO) energy level less sterically accessible for electron transfer. ${ }^{4,39,40}$ A fluorene core with two aliphatic side chains at the 9-position and the deep-lying highest occupied molecular orbital (HOMO) energy level are advantageous for improving the solubility of the molecule and facilitating charge transport in the case of devices. The $\pi$-conjugation of fluorene was extended by incorporating benzothiadiazole at the 2,7-positions of the alkylated fluorene. Benzothiadiazole, which is a fused heteroaromatic molecule, has strong electron-withdrawing properties; thus, it increases the electron-deficient character toward the outside of the molecule. The introduction of benzothiadiazole lowers the LUMO energy level of fluorene as well, which may result in high $V_{\mathrm{oc}}$ in solar cells. Fluorene-2,1,3benzothiadiazole has strong light absorption, high charge carrier mobility, and good thermodynamic stability because of its coplanar molecular structure with strong $\pi-\pi$ and $\sigma-\sigma$ interactions similar to tetrathiafulvalenes (TTFs) and diathiafulvalene (DTFs). ${ }^{41}$ Introduction of hexadiathiafulvalene (HDT) to fluorene-2,1,3-benzthiadizole extends the $\pi$-electron conjugation in the molecular backbone, which is expected to promote the charge-transport mechanism and provide a broader absorption in the UV-vis region.

The photovoltaic performance of BAF-2HDT has been investigated in an inverted structure $\mathrm{BHJ}$ solar cell blending with a low band gap conjugated polymer poly[(5,6-difluoro2,1,3-benzothiadiazol-4,7-diyl)-alt-(3,3"' -di(2-octyldodecyl) $2,2^{\prime} ; 5^{\prime}, 2^{\prime \prime} ; 5^{\prime \prime}, 2^{\prime \prime \prime}$-quaterthiophen-5,5"'-diyl)] (PffBT4T-2OD), commonly known as PCE11 (Figure 1). A systematic study on structural, optical, and electrochemical properties of the BAF2HDT molecule and the photovoltaic performance of PffBT4T-2OD:BAF-2HDT-based BHJ solar cells is reported here.

\section{EXPERIMENTAL SECTION}

2.1. Synthesis and Characterization of BAF-2HDT. The synthetic route of BAF-2HDT is illustrated in the Supporting Information. Reaction of 9,9-didecyllfluorene-2,7-diboronic acid pinacol ester with electron-withdrawing bromo-2,1,3benzothiadiazole-4-carboxaldehyde by a Suzuki coupling reaction catalyzed by $\left[\mathrm{Pd}\left(\mathrm{PPh}_{3}\right)_{4}\right]$ afforded the aryl dialdehyde intermediate (BAF-2CHO). The HDT group introduced through a Horner-Wittig reaction provided BAF-2HDT with a dark pink color. The introduction of HDT in BAF-2CHO induced a color change of the acceptors toward a more visible region (red shift). This molecule shows good solubility in common organic solvents such as chloroform, THF, and dichloromethane at room temperature. The structure and purity of BAF-2HDT have been characterized and confirmed by ${ }^{1} \mathrm{H}$ NMR, ${ }^{13} \mathrm{C}$ NMR, and MALDI-TOF MS measurements. The results are available in the Supporting Information.

2.2. OPV Device Fabrication. Patterned indium tin oxide (ITO) coated glass substrates were used as the transparent bottom electrode, i.e., the cathode. The substrates were first thoroughly cleaned with detergent and then ultrasonicated with deionized (DI) water, acetone and 2-propanol consecutively for $15 \mathrm{~min}$ each and subsequently dried under a flow of anhydrous nitrogen. After ultraviolet/ozone treatment for $15 \mathrm{~min}$, a seed layer of zinc oxide $(\mathrm{ZnO})$, which was previously synthesized by the method reported elsewhere, was spin-coated on precleaned ITO substrates at $5000 \mathrm{rpm}$ for $30 \mathrm{~s}$ to obtain a film thickness of approximately $40 \mathrm{~nm}$. PffBT4T-2OD (1-materials), $o$ dichlorobenzene (o-DCB), diiodooctane (DIO), and chlorobenzene (CB) (Aldrich), molybdenum oxide $\left(\mathrm{MoO}_{3}\right)$ (Alfa Aesar, 99.9995\%), and silver (Alfa Aesar, 99.99\%) were used. At first, PffBT4T-2OD (10 mg) and BAF-2HDT (13-17 mg) were initially dissolved in $1 \mathrm{~mL}$ of mixed solvent $o$-DCB/CB/ DIO (1:1:0.03). The solution was allowed to stir for at least $6 \mathrm{~h}$ at $80{ }^{\circ} \mathrm{C}$. Thereafter, $\mathrm{ZnO}$-coated ITO substrates were preheated on a hot plate at $110{ }^{\circ} \mathrm{C}$. A photoactive blend was spin-coated at $800 \mathrm{rpm}$ for $20 \mathrm{~s}$ to give rise to a film thickness of $\sim 290 \mathrm{~nm}$. The active layer was either (i) thermally annealed at $80{ }^{\circ} \mathrm{C}$ for $15 \mathrm{~min}$ or (ii) placed in the antechamber of the glovebox under vacuum at room temperature for $2 \mathrm{~h}$. Finally, 
(a)

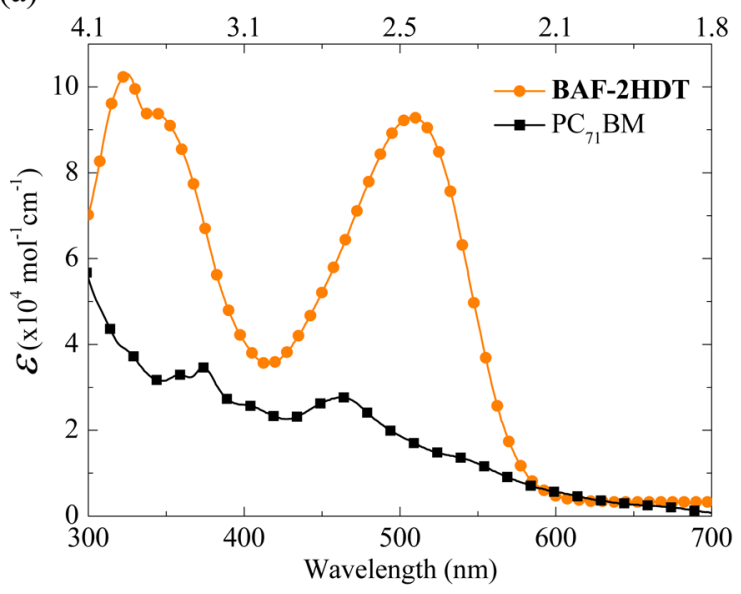

(b)

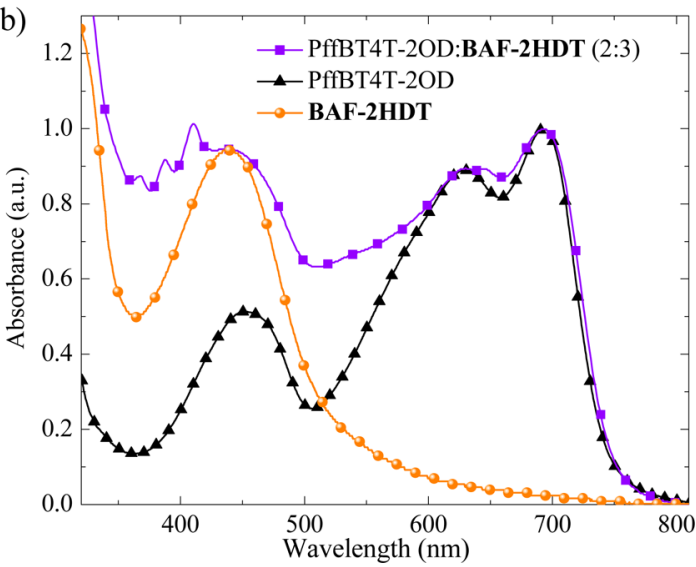

Figure 2. (a) UV-vis spectra of BAF-2HDT (orange) and $\mathrm{PC}_{71} \mathrm{BM}$ (black) in chloroform solution. (b) Normalized thin film absorption profile of pristine PffBT4T-2OD (black), BAF-2HDT (orange), and PffBT4T-2OD:BAF-2HDT blend (violet).

$20 \mathrm{~nm} \mathrm{MoO}_{3}$ and $100 \mathrm{~nm}$ silver $(\mathrm{Ag})$ were evaporated using the shadow mask by thermal evaporation to form the anode. All cells were encapsulated using epoxy inside the $\mathrm{N}_{2}$-filled glovebox.

2.3. Device Characterization. The current densityvoltage $(J-V)$ characteristics of the devices were measured by a Keithley 2420 semiconductor device parameter analyzer. The light $J-V$ curves were recorded under standard 1 sun illumination of $100 \mathrm{~mW} \cdot \mathrm{cm}^{-2}$ light intensity of a xenon arc lamp based solar simulator (SCIENCETECH SS 150 Solar Simulator) using AM 1.5G filter. The light intensity of the solar simulator was calibrated with a standard monocrystalline silicon reference cell. The external quantum efficiency (EQE) of the solar cells was measured with a standard lock-in amplifier after the device area was illuminated with monochromator light from a tungsten lamp. All the measurements were performed under ambient conditions.

\section{RESULTS AND DISCUSSION}

3.1. UV-vis Absorption Spectra. The UV-vis absorption spectrum of BAF-2HDT in chloroform $\left(\mathrm{CHCl}_{3}\right)$ solution with concentration $0.01 \mathrm{mg} \cdot \mathrm{mL}^{-1}$ is shown in Figure $2 \mathrm{a}$ along with that of $\mathrm{PC}_{71} \mathrm{BM}$. The BAF-2HDT shows absorption in the wavelength range of $300-600 \mathrm{~nm}$ with a maximum absorption peak at $509 \mathrm{~nm}$. The $\varepsilon$ value at this wavelength was calculated to be $9.32 \times 10^{4} \mathrm{M}^{-1} \cdot \mathrm{cm}^{-1}$, whereas the $\varepsilon$ value for $\mathrm{PC}_{71} \mathrm{BM}$ is $2.8 \times 10^{4} \mathrm{M}^{-1} \cdot \mathrm{cm}^{-1}$. The molecule also has two very closely lying peaks at 324 and $345 \mathrm{~nm}$. In comparison with fullerenebased acceptors that absorb more near UV, ${ }^{42}$ BAF-2HDT molecules absorb in the visible region as well and, hence, provide a great advantage in terms of absorption of solar energy. The PffBT4T-2OD:BAF-2HDT blend film also shows good absorption throughout the entire $\mathrm{UV}-$ vis region as shown in Figure $2 b$ (orange curve).

3.2. Electrochemical Behavior. The electrochemical behavior of the BAF-2HDT acceptor was studied by cyclic voltammetry $(\mathrm{CV})$ in dichloromethane (DCM) solution (Figure 3). BAF-2HDT was dissolved in DCM containing $0.1 \mathrm{M}$ tetrabutylammonium perchlorate (TBAP) as a supporting electrolyte at a concentration of $10^{-3} \mathrm{M} . \mathrm{Ag} / \mathrm{AgCl}$ (calomel) was used as a reference electrode, while ferrocene was used as a standard compound. The value of the HOMO energy level of BAF-2HDT was estimated from the onset of

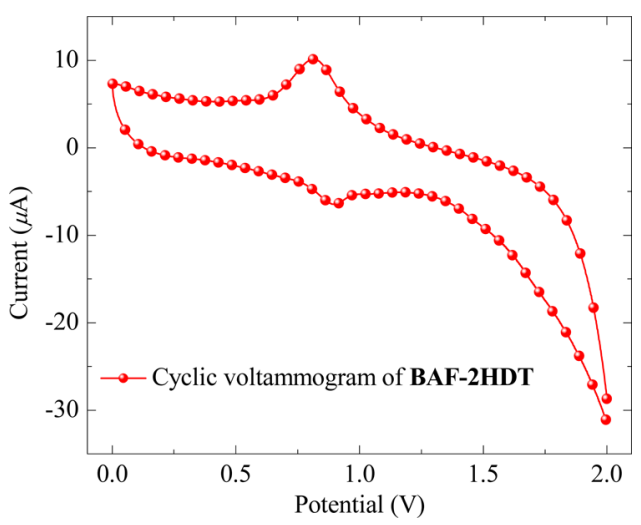

Figure 3. Cyclic voltammogram for BAF-2HDT; the onset oxidation potential $\left(E_{\text {oxd }}\right)$ is measured in DCM solvent, potential $(\mathrm{V})$ vs $F_{\mathrm{c}} / F_{\mathrm{c}}{ }^{+}$ (internal standard) tetrabutylammonium perchlorate (TBAP, $0.1 \mathrm{M}$ ) as the supporting electrolyte: reference electrode $(\mathrm{Ag} / \mathrm{AgCl})$, counter electrode (Pt wire), and working electrode (glassy carbon).

oxidation, and its LUMO level was calculated by the corresponding HOMO level and optical band gap $\left(E_{0-0}\right)$, which was measured from the tangent of the absorption spectrum. The values of the HOMO and LUMO energy levels of BAF-2HDT are found to be -5.69 and $-3.58 \mathrm{eV}$, respectively. These values are well synchronized with most of the low-band gap polymers used as the donor for OPV device fabrication.

3.3. Photovoltaic Performance. The BHJ solar cells were fabricated in inverted architecture with the device configuration of the ITO/ZnO/active layer $/ \mathrm{MoO}_{3} / \mathrm{Ag}$ using PffBT4T-2OD as an electron donor and BAF-2HDT as the acceptor (see the Experimental Section). The device structure and corresponding energy band diagram are schematically illustrated in parts a and b, respectively, of Figure 4. The devices were tested under 100 $\mathrm{mW} \cdot \mathrm{cm}^{-2}$ air mass 1.5 global (AM $1.5 \mathrm{G}$ ) solar illumination. The devices were fabricated with different PffBT4T-2OD:BAF2HDT weight ratios and additive concentrations. The optimized D/A ratio was found to be $1: 1.5 \mathrm{w} / \mathrm{w}$, whereas the $3 \%(\mathrm{v} / \mathrm{v})$ content of DIO in the active layer blend solution gave rise to best photovoltaic performance of the device (Table S1). The active layer was either (i) thermally annealed at $80{ }^{\circ} \mathrm{C}$ for $15 \mathrm{~min}$ (conventional fast solvent evaporation) or (ii) placed in 
(a)

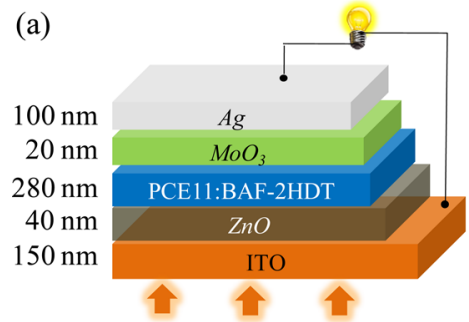

(b)

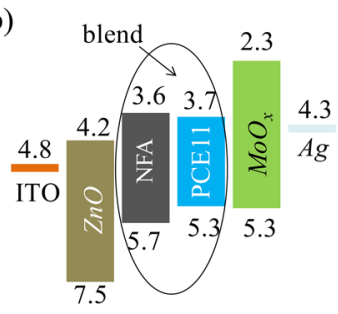

Figure 4. (a) Schematic of PffBT4T-2OD:BAF-2HDT BHJ in inverted device configuration: ITO/ZnO/PffBT4T-2OD:BAF$2 \mathrm{HDT} / \mathrm{MoO}_{3} / \mathrm{Ag}$. Cross-sectional view shows the different constituent layers along with their thicknesses. (b) Energy band diagram of the device. All energy values are negative with respect to vacuum level.

an antechamber of the glovebox under vacuum at room temperature for $2 \mathrm{~h}$ to facilitate slow solvent evaporation.

Figure 5a shows the current-density vs voltage $(J-V)$ characteristics of PffBT4T-2OD:BAF-2HDT (1:1.5 w/w) based BHJ solar cells made from "thermally annealed" and "vacuum-dried" photoactive layers, and the photovoltaic parameters have been summarized in Table 1 . The "thermally annealed" devices have an average PCE of $5.31 \%$ and a maximum PCE of $5.51 \%$ with an open circuit voltage $\left(V_{\text {oc }}\right)$ of $0.76 \mathrm{~V}$, short-circuit current density $\left(J_{\mathrm{sc}}\right)$ of $13.69 \mathrm{~mA} \cdot \mathrm{cm}^{-2}$, and fill factor (FF) of 0.53 . The PCE was significantly improved

for the devices where the active layer was dried in vacuo with an average PCE of $7.04 \%$ and a maximum PCE of $7.13 \%, J_{\mathrm{sc}}$ of $14.64 \mathrm{~mA} \cdot \mathrm{cm}^{-2}, V_{\text {oc }}$ of $0.77 \mathrm{~V}$, and FF of 0.64 . As can be seen from Table 1, a significant enhancement of $\sim 30 \%$ in PCE is obtained by slow solvent evaporation, thereby facilitating the gradual self-organization of the PffBT4T-2OD:BAF-2HDT blend. The FF is enhanced by $21 \%$ with vacuum drying treatment (Table 1), which suggests that the slow drying of the film could be a critical factor for improving FF in the case of NFA-based BHJ solar cells. A decrease in the value of series resistance $\left(R_{\mathrm{s}}\right)$ from 16.1 to $4.5 \Omega \cdot \mathrm{cm}^{2}$ and an increase in the shunt resistance $\left(R_{\mathrm{sh}}\right)$ from 0.4 to $0.5 \mathrm{k} \Omega \cdot \mathrm{cm}^{2}$ in the "vacuumdried" devices as compared to "thermally annealed" samples indicates better charge transport in $\mathrm{BHJ}$ film. The statistical histogram of PCEs obtained from each category of devices is illustrated in Figure $5 b$, and the corresponding photovoltaic parameters have been tabulated in Table S2. The OPV devices also have been made from "as cast" films without any further postfilm formation treatment from the same run (under similar experimental conditions), and the corresponding characteristic $J-V$ curve is presented in Figure S1. The "as cast" device shows a PCE of $3.7 \%$ with lower $J_{\mathrm{sc}}$ and FF of $10.7 \mathrm{~mA} \cdot \mathrm{cm}^{-2}$ and 0.45 , respectively. Solar cells cast from annealed active layer without any additive show comparatively better photovoltaic performance than the "as cast" samples. The best performing solar cell from this set of devices shows a PCE of $4.5 \%$ with $J_{\text {sc }}$ of 11.89
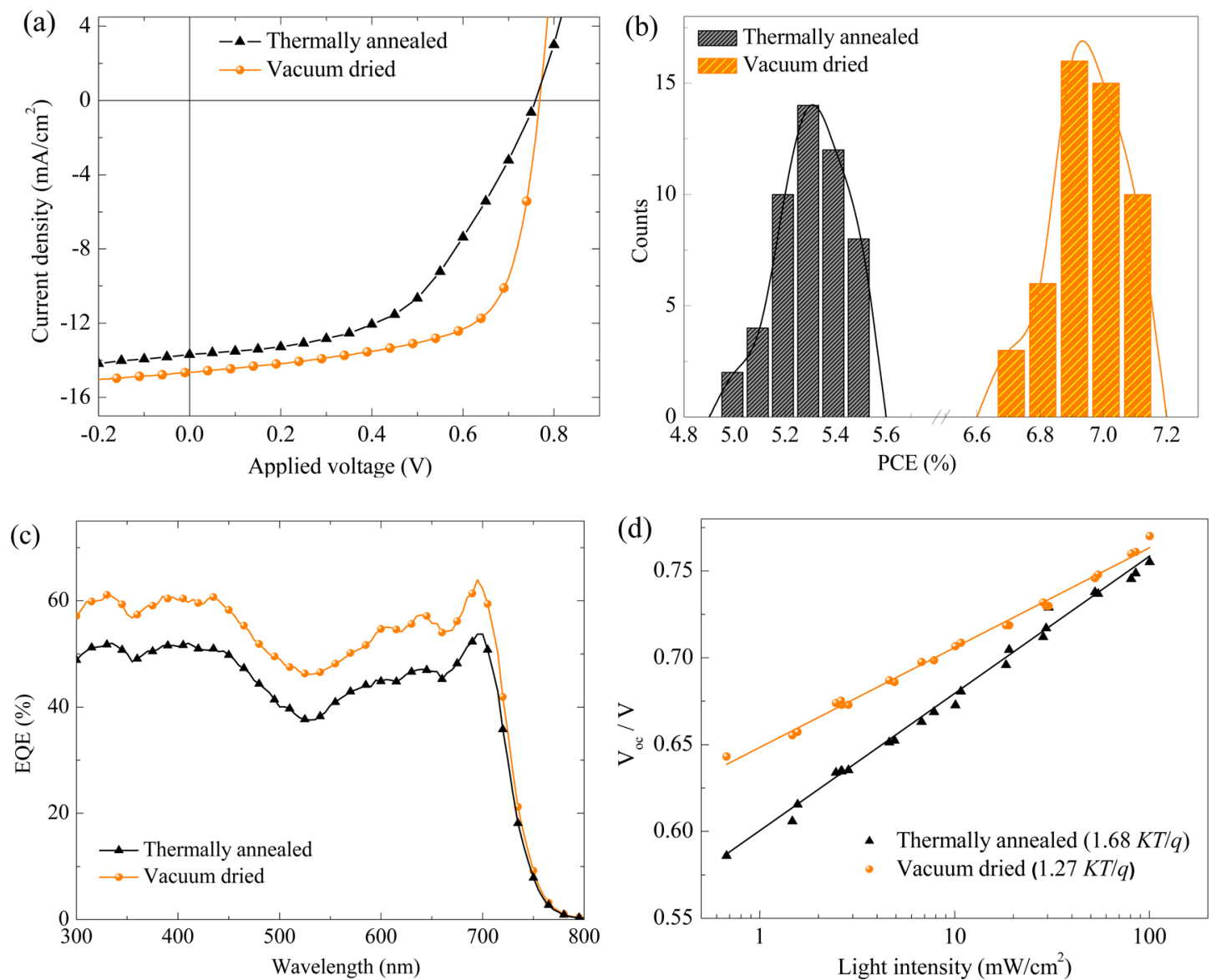

Figure 5. (a) Characteristic current density versus voltage $(J-V)$ curves of inverted structure solar cells with device configuration of ITO/ZnO/ PffBT4T-2OD:BAF-2HDT $/ \mathrm{MoO}_{3} / \mathrm{Ag}$ fabricated from "vacuum-dried" and "thermally annealed" photo-active layers, (b) Statistical histogram of PCEs of the respective polymer solar cells (50 devices for each case), (c) the EQE curves of both categories of solar cells, (d) dependence of Voc on incident light intensity $(I)$ as observed during $J-V$ characterization of the devices. 
Table 1. Photovoltaic Parameters of PffBT4T-2OD:BAF-2HDT-Based BHJ Solar Cells ${ }^{a}$

\begin{tabular}{lccccccccc}
\multicolumn{1}{c}{ treatments } & $\left.J_{\mathrm{sc}}(\mathrm{mAcm})^{-2}\right)$ & $V_{\mathrm{oc}}(\mathrm{V})$ & FF & PCE $(\%)$ & $R_{\mathrm{S}}\left(\Omega \cdot \mathrm{cm}^{2}\right)$ & $R_{\mathrm{SH}}\left(\mathrm{k} \Omega \cdot \mathrm{cm}^{2}\right)$ & $k T / q$ & $\mu_{\mathrm{h}}\left(\mathrm{cm}^{2} \cdot \mathrm{V}^{-1} \cdot \mathrm{s}^{-1}\right)$ & $\mu_{\mathrm{n}}\left(\mathrm{cm}^{2} \cdot \mathrm{V}^{-1} \cdot \mathrm{s}^{-1}\right)$ \\
thermally annealed & 13.69 & 0.76 & 0.53 & 5.51 & 16.1 & 0.4 & 1.68 & $2.1 \times 10^{-4}$ & $1.4 \times 10^{-4}$ \\
vacuum dried & 14.64 & 0.77 & 0.64 & 7.13 & 4.5 & 0.5 & 1.27 & $2.7 \times 10^{-4}$ & $3.5 \times 10^{-4}$
\end{tabular}

${ }^{a_{T}}$ The solar cell devices were tested under $100 \mathrm{~mW} \cdot \mathrm{cm}^{-2}$ air mass 1.5 global (AM $1.5 \mathrm{G}$ ) solar illumination.
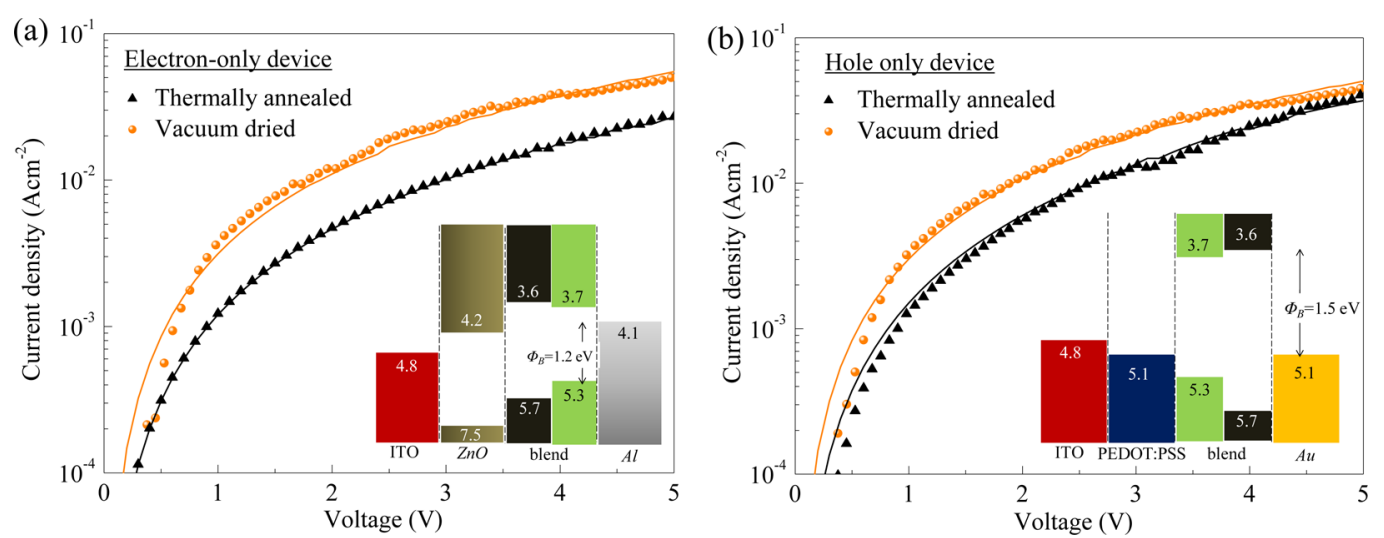

Figure 6. Current density-voltage characteristics and corresponding SCLC fitting of (a) electron-only and (b) hole-only devices made from both "thermally annealed" and "vacuum-dried" PffBT4T-2OD:BAF-2HDT BHJ films. Inset: energy band diagram of the corresponding devices.

$\mathrm{mA} \cdot \mathrm{cm}^{-2}$ and FF of 0.49 (Figure S1 and Table S3). However, no significant change was found in the value of $V_{\text {oc }}$.

3.4. SpectralResponse. The "thermally annealed" PffBT4T-2OD:BAF-2HDT BHJ solar cell exhibited a maximum external quantum efficiency (EQE) of $54 \%$ at $696 \mathrm{~nm}$ as shown in Figure 5c. The EQE value approaches $64 \%$ at $696 \mathrm{~nm}$ for the "vacuum-dried" device. The $J_{\text {sc }}$ calculated from integration of the EQE spectrum from 300 to $800 \mathrm{~nm}$ is 14.5 $\mathrm{mA} \cdot \mathrm{cm}^{-2}$, in good agreement (ca. $1 \%$ error) with $J_{\mathrm{sc}}$ of 14.64 $\mathrm{mA} \cdot \mathrm{cm}^{-2}$ obtained from the light $J-V$ curve. Interestingly, a consistent EQE value of $60 \%$ was observed in the wavelength range between 300 and $450 \mathrm{~nm}$ due to a large absorption of BAF-2HDT.

3.5. Charge Recombination Study. The charge recombination mechanism in our devices has been studied by recording the value of $V_{\mathrm{oc}}$ at different incident light intensities during $J-V$ measurements. Figure 5d shows the dependence of $V_{\text {oc }}$ on the incident light intensity $(I)$ in a semilogarithmic plot, the slope of which defines the degree of trap-assisted Shockley-ReadHall (SRH) recombination in the BHJ solar cell. ${ }^{43,44}$ In the case of strong trap-assisted recombination, it was observed that the slope of $V_{\text {oc }}$ vs $\ln (I)$ linear fit is close to $2 k T / q$, where $k$ is Boltzmann's constant, $T$ is absolute temperature, and $q$ is elementary charge. ${ }^{45-47}$ In our case, the OSC fabricated from "thermally annealed" PffBT4T-2OD:BAF-2HDT blend film shows a slope of $1.68 \mathrm{kT} / \mathrm{q}$ that indicates strong $\mathrm{SRH}$ recombination. On the other hand, a "vacuum-dried" PffBT4T-2OD:BAF-2HDT solar cell obtains a smaller slope of $1.27 \mathrm{kT} / \mathrm{q}$ only. These findings are consistent with the decreased value of $R_{\mathrm{s}}$ and an increased value of $R_{\mathrm{sh}}$ in the "vacuum-dried" devices as compared to "thermally annealed" samples (Table 1) as obtained from analysis of light $J-V$ characteristics. The lower value of $K T / q$ is an indication of improved film morphology and favorable phase segregation of the blend layer (also confirmed by grazing incidence X-ray diffraction spectroscopy, Figure S2 in SI), which facilitates charge transport and an improved metal-organic interface, which aids charge collection.
3.6. Charge Carrier Mobility. The bulk electron and hole mobility of the PffBT4T-2OD:BAF-2HDT blend system were measured by Mott-Gurney's space-charge-limited current (SCLC) method. The structures of electron-only and holeonly devices for SCLC measurements were ITO/ZnO/active layer/Al and ITO/PEDOT:PSS/active layer/Au, respectively. The measured $J-V$ curves and Mott-Gurney equation fitting of the data are shown in Figure 6 for the two processing conditions: thermally $\left(80^{\circ} \mathrm{C}\right)$ annealed and vacuum-dried $\mathrm{BHJ}$ films. The hole mobility $\left(\mu_{\mathrm{h}}\right)$ of the donor polymer (PffBT4T2OD) in the "thermally annealed" blends is found to be $2.1 \times$ $10^{-4} \mathrm{~cm}^{2} \cdot \mathrm{V}^{-1} \cdot \mathrm{s}^{-1}$, which is marginally increased after vacuum drying to $2.7 \times 10^{-4} \mathrm{~cm}^{2} \cdot \mathrm{V}^{-1} \cdot \mathrm{s}^{-1}$. However, the electron mobility increases significantly from $1.4 \times 10^{-4} \mathrm{~cm}^{2} \cdot \mathrm{V}^{-1} \cdot \mathrm{s}^{-1}$ in the "thermally annealed" blend films to $3.5 \times 10^{-4} \mathrm{~cm}^{2} \cdot \mathrm{V}^{-1} \cdot \mathrm{s}^{-1}$ in the case of "vacuum-dried" blends, which possibly contributed to the improvement in the FF from 53\% to 64\%. It is important to note that the observed hole and electron mobilties are significantly balanced in both "thermally annealed" $\left(\mu_{\mathrm{e}} / \mu_{\mathrm{h}}=0.7\right)$ and "vacuum-dried" blend devices $\left(\mu_{\mathrm{e}} / \mu_{\mathrm{h}}=1.3\right)$.

3.7. Photoluminescence Spectra. Photoluminescence (PL) measurements were carried out on the blend in $o$ $\mathrm{DCB} / \mathrm{CB} / \mathrm{DIO}(1: 1: 0.03)$ mixed solvent with increasing concentration of BAF-2HDT in order to scrutinize the charge separation and photoinduced electron transfer from the donor to the NFA molecule. Figure 7 shows the PL spectra for the PffBT4T-2OD:BAF-2HDT blend solution with different donor-acceptor weight ratios starting from 1:0 (pristine PffBT4T-2OD) to $1: 1.75$. As can be noticed, a PL maximum of the pristine PffBT4T-2OD at around $738 \mathrm{~nm}$ when excited at $530 \mathrm{~nm}$ corresponds to the radiative decay of excitons to the ground state. ${ }^{48}$ However, a consistent and significant decrease in the PL peak intensity was observed for the PffBT4T2OD:BAF-2HDT blend solution with a gradual increase in the acceptor content. This quenching of PL peak can be attributed to the exciton dissociation due to a very efficient intramolecular charge transfer from PffBT4T-2OD to BAF-2HDT. The PL emission of blend solution was quenched with a quenching 


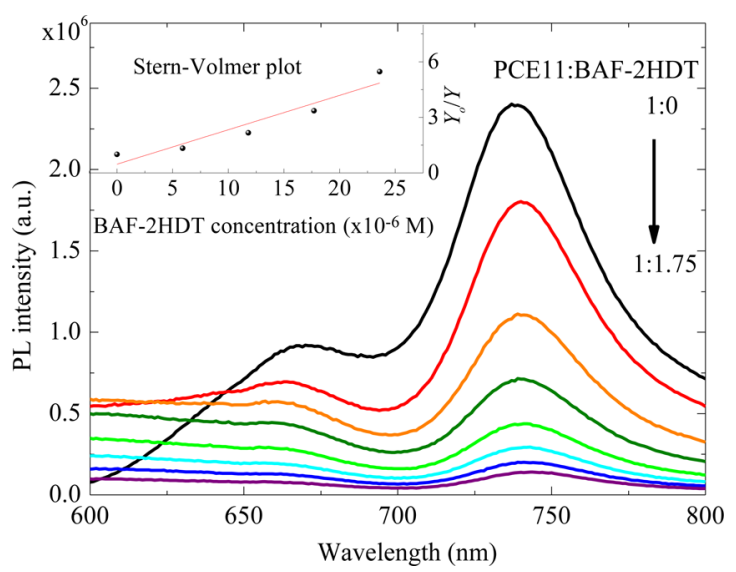

Figure 7. Photoluminescence quenching spectra of PffBT4T2OD:BAF-2HDT blend solution in $o$-DCB:CB:DIO (1:1:0.03) cosolvent with increasing concentrations of BAF-2HDT with D/A weight ratio in the blend solution varying from 1:0 to $1: 1.75$. Inset: Stern-Volmer quenching plot for the BAF-2HDT.

efficiency (PLQE) of 94\% at the acceptor concentration of only $4 \times 10^{-5} \mathrm{M}$ relative to pure PffBT4T-2OD in solution. To investigate the quenching ability of BAF-2HDT, the SternVolmer quenching plot has been drawn further (inset of Figure 7) using the relation $Y_{\mathrm{o}} / Y=1+K_{\mathrm{sv}} \mathrm{c}(\mathrm{BAF}-2 \mathrm{HDT})$, where $Y_{\mathrm{o}}$ and $Y$ are the PL quantum yields of pure donor and donor/ acceptor blend, respectively. The plot shows a nearly linear regime up to the BAF-2HDT concentration of $2.3 \times 10^{-5} \mathrm{M}^{-1}$. The Stern-Volmer quenching constant $\left(K_{\mathrm{sv}}\right)$ was calculated to be $1.8 \times 10^{5} \mathrm{M}^{-1}$, which is much higher compared to values reported for other fullerene acceptors, generally in the range between $10^{3}$ and $10^{4} \mathrm{M}^{-1}$. 9 A similar kind of PL quenching behavior was also observed in the solid state by exciting both the donor and acceptor individually (Figure S3). Thus, the PL quenching results indicate a highly efficient photoinduced charge transfer from donor to BAF-2HDT in both solution and thin films.

3.8. Atomic Force Microscopy. Nanomorphology of the photoactive layer plays a crucial role in the improvement the charge-carrier transport inside the active layer and determining the photovoltaic performance of OPVs. The mesoscale surface morphology was investigated by atomic force microscopy (AFM). Parts a and $b$ of Figure 8 represent the AFM images of "thermally annealed" and "vacuum-dried" PffBT4T-2OD:BAF2HDT composite films, respectively. The PffBT4T-2OD:BAF2HDT blend film without vacuum-drying treatment shows a rougher surface with a root-mean-square (RMS) roughness of $2.9 \mathrm{~nm}$ with large pin holes, whereas in the case of "vacuumdried" films the pin holes are reduced and it shows a smooth surface with RMS roughness of $1.4 \mathrm{~nm}$, which resulted in an enhancement in the PCE after vacuum drying of the samples. The internal morphology of the PffBT4T-2OD:BAF-2HDT blend film was further examined by transmission electron microscopy (TEM), and the image is displayed in Figure 8c,d. However, the TEM images did not show any noticeable difference in the nanostructure level. The high uniformity indicates good compatibility and miscibility of BAF-2HDT with the donor molecule PffBT4T-2OD.

\section{CONCLUSION}

We have designed and developed a solution-processable, smallmolecule non-fullerene acceptor BAF-2HDT containing

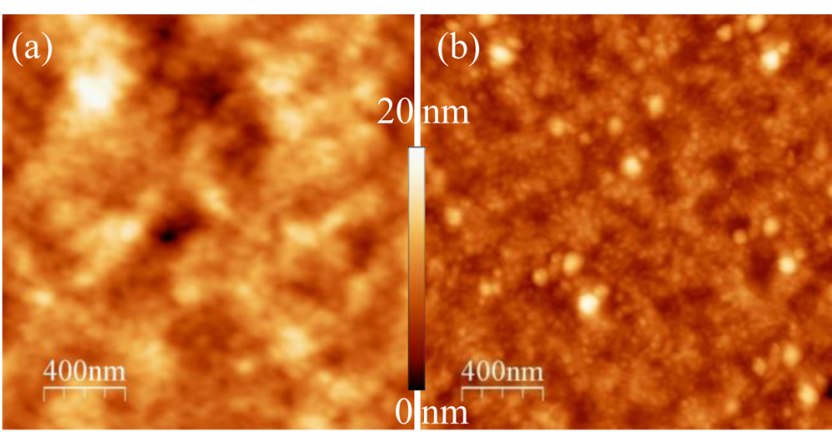

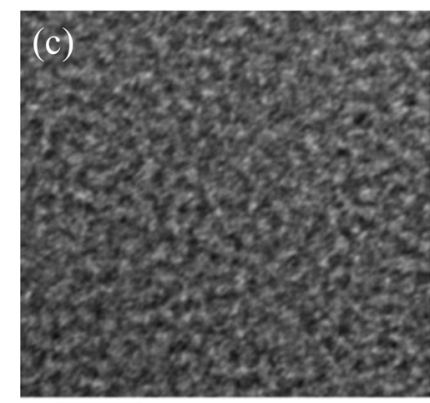

$\overline{5 \mathrm{~nm}}$

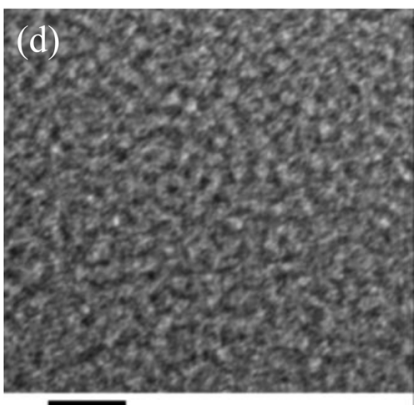

$\overline{5 \mathrm{~nm}}$
Figure 8. AFM height images of PffBT4T-2OD:BAF-2HDT active layers subjected to (a) thermal annealing and (b) vacuum drying treatment after spin coating; TEM images of the (c) "thermally annealed" and (d) "vacuum-dried" blend films.

fluorene as a central block unit, and HDT as the end-capping group led to a broad band absorption from 300 to $580 \mathrm{~nm}$ with maximum absorbance at $509 \mathrm{~nm}$ and high $\varepsilon$ value as compared $\mathrm{PC}_{71} \mathrm{BM}$. The BAF-2HDT has a very good electron-accepting nature with a $K_{\mathrm{sv}}$ value of $1.8 \times 10^{5} \mathrm{M}^{-1}$ as confirmed by PL quenching experiments. It is shown that the vacuum-drying technique gives better morphology as compared to conventional annealing technique, and a $\mathrm{BHJ}$ solar cell with PffBT4T2OD as the donor and BAF-2HDT as the acceptor gave a maximum PCE of 7.13\%. Thus, the molecule fluorene-2,1,3benzothiadiazole with HDT as the end-capping groups, having strong light absorption, high charge carrier mobility, and good thermodynamic stability because of its coplanar molecular structure with strong $\pi-\pi$ and $\sigma-\sigma$ interactions, could be an excellent electron-acceptor candidate as a substitute of fullerene derivatives in low-cost solution-processable organic photovoltaics.

\section{ASSOCIATED CONTENT}

\section{S Supporting Information}

The Supporting Information is available free of charge on the ACS Publications website at DOI: 10.1021/acs.jpcc.6b07778.

Experimental details of UV-visible absorption spectroscopy, electrochemical characterization, photovoltaic results of the OSCs with variation in donor-to-acceptor weight ratio, device performance of reference solar cells, grazing incidence X-ray diffraction spectroscopy of differently treated films, photoluminescence in solid state, experimental details on synthesis of fullerene acceptors, and structural characterization by ${ }^{1} \mathrm{H}$ NMR, ${ }^{13} \mathrm{C}$ NMR, ESI-MS, and MALDI-TOF (PDF) 


\section{AUTHOR INFORMATION}

\section{Corresponding Authors}

*E-mail: spsingh@iict.res.in.

*E-mail: drvinaygupta@netscape.net.

\section{Author Contributions}

"S.B. and A.B. contributed equally.

\section{Author Contributions}

S.P.S. designed the molecule and supervised and directed project. Suman synthesized the NFA molecule. V.G. and A.B. fabricated and characterized solar cell devices. All of the authors contributed to writing the manuscript.

Notes

The authors declare no competing financial interest.

\section{ACKNOWLEDGMENTS}

We acknowledge financial support from the Indo-UK APEX project (Phase-II).

\section{REFERENCES}

(1) Facchetti, A. $\pi$-Conjugated Polymers for Organic Electronics and Photovoltaic Cell Applications. Chem. Mater. 2011, 23, 733-758.

(2) Jiang, W.; Li, Y.; Wang, Z. Tailor-Made Rylene Arrays for High Performance n-Channel Semiconductors. Acc. Chem. Res. 2014, 47, 3135-3147.

(3) Günes, S.; Neugebauer, H.; Sariciftci, N. S. Conjugated PolymerBased Organic Solar Cells. Chem. Rev. 2007, 107, 1324-1338.

(4) Lin, Y.; Zhao, F.; He, Q.; Huo, L.; Wu, Y.; Parker, T. C.; Ma, W.; Sun, Y.; Wang, C.; Zhu, D.; et al. High-Performance Electron Acceptor with Thienyl Side Chains for Organic Photovoltaics. J. Am. Chem. Soc. 2016, 138, 4955-4961.

(5) Brunetti, F. G.; Kumar, R.; Wudl, F. Organic Electronics from Perylene to Organic Photovoltaics: Painting a Brief History with a Broad Brush. J. Mater. Chem. 2010, 20, 2934-2948.

(6) Eftaiha, A. a. F.; Sun, J.-P.; Hill, I. G.; Welch, G. C. Recent Advances of Non-Fullerene, Small Molecular Acceptors for Solution Processed Bulk Heterojunction Solar Cells. J. Mater. Chem. A 2014, 2, 1201-1213.

(7) Jiang, W.; Ye, L.; Li, X.; Xiao, C.; Tan, F.; Zhao, W.; Hou, J.; Wang, Z. Bay-Linked Perylene Bisimides as Promising Non-Fullerene Acceptors for Organic Solar Cells. Chem. Commun. 2014, 50, 10241026.

(8) Kippelen, B.; Bredas, J.-L. Organic Photovoltaics. Energy Environ. Sci. 2009, 2, 251-261.

(9) Lin, Y.; Li, Y.; Zhan, X. Small Molecule Semiconductors for HighEfficiency Organic Photovoltaics. Chem. Soc. Rev. 2012, 41, 42454272.

(10) Mishra, A.; Bäuerle, P. Small Molecule Organic Semiconductors on the Move: Promises for Future Solar Energy Technology. Angew. Chem., Int. Ed. 2012, 51, 2020-2067.

(11) Li, H.; Earmme, T.; Subramaniyan, S.; Jenekhe, S. A. Bis(Naphthalene Imide)diphenylanthrazolines: A New Class of Electron Acceptors for Efficient Nonfullerene Organic Solar Cells and Applicable to Multiple Donor Polymers. Adv. Energy Mater. 2015, $5,1402041$.

(12) Li, H.; Hwang, Y.-J.; Courtright, B. A. E.; Eberle, F. N.; Subramaniyan, S.; Jenekhe, S. A. Fine-Tuning the 3D Structure of Nonfullerene Electron Acceptors Toward High-Performance Polymer Solar Cells. Adv. Mater. 2015, 27, 3266-3272.

(13) Nielsen, C. B.; Holliday, S.; Chen, H.-Y.; Cryer, S. J.; McCulloch, I. Non-Fullerene Electron Acceptors for Use in Organic Solar Cells. Acc. Chem. Res. 2015, 48, 2803-2812.

(14) Zhao, W.; Qian, D.; Zhang, S.; Li, S.; Inganäs, O.; Gao, F.; Hou, J. Fullerene-Free Polymer Solar Cells with over $11 \%$ Efficiency and Excellent Thermal Stability. Adv. Mater. 2016, 28, 4734-4739.
(15) Ball, M.; Zhong, Y.; Wu, Y.; Schenck, C.; Ng, F.; Steigerwald, M.; Xiao, S.; Nuckolls, C. Contorted Polycyclic Aromatics. Acc. Chem. Res. 2015, 48, 267-276.

(16) Guo, X.; Facchetti, A.; Marks, T. J. Imide- and AmideFunctionalized Polymer Semiconductors. Chem. Rev. 2014, 114, 8943-9021.

(17) Sharenko, A.; Proctor, C. M.; van der Poll, T. S.; Henson, Z. B.; Nguyen, T.-Q.; Bazan, G. C. A High-Performing Solution-Processed Small Molecule:Perylene Diimide Bulk Heterojunction Solar Cell. Adv. Mater. 2013, 25, 4403-4406.

(18) Lin, H.; Chen, S.; Hu, H.; Zhang, L.; Ma, T.; Lai, J. Y. L.; Li, Z.; Qin, A.; Huang, X.; Tang, B.; et al. Reduced Intramolecular Twisting Improves the Performance of 3D Molecular Acceptors in NonFullerene Organic Solar Cells. Adv. Mater. 2016, 1-6.

(19) Liu, Y.; Lai, J. Y. L.; Chen, S.; Li, Y.; Jiang, K.; Zhao, J.; Li, Z.; Hu, H.; Ma, T.; Lin, H.; et al. Efficient Non-Fullerene Polymer Solar Cells Enabled by Tetrahedron-Shaped Core based 3D-Structure SmallMolecular Electron Acceptors. J. Mater. Chem. A 2015, 3, 1363213636.

(20) Zhao, J.; Li, Y.; Lin, H.; Liu, Y.; Jiang, K.; Mu, C.; Ma, T.; Lin Lai, J. Y.; Hu, H.; Yu, D.; et al. High-Efficiency Non-Fullerene Organic Solar Cells Enabled by a Difluorobenzothiadiazole-based Donor Polymer Combined with a Properly Matched Small Molecule Acceptor. Energy Environ. Sci. 2015, 8, 520-525.

(21) Jung, J. W.; Liu, F.; Russell, T. P.; Jo, W. H. A High Mobility Conjugated Polymer Based on Dithienothiophene and Diketopyrrolopyrrole for Organic Photovoltaics. Energy Environ. Sci. 2012, 5, 6857-6861.

(22) Li, H.; Earmme, T.; Ren, G.; Saeki, A.; Yoshikawa, S.; Murari, N. M.; Subramaniyan, S.; Crane, M. J.; Seki, S.; Jenekhe, S. A. Beyond Fullerenes: Design of Nonfullerene Acceptors for Efficient Organic Photovoltaics. J. Am. Chem. Soc. 2014, 136, 14589-14597.

(23) Lin, Y.; Cheng, P.; Li, Y.; Zhan, X. A 3D Star-Shaped NonFullerene Acceptor for Solution-Processed Organic Solar Cells with a High Open-Circuit Voltage of 1.18 V. Chem. Commun. 2012, 48, 4773-4775.

(24) Patil, H.; Zu, W. X.; Gupta, A.; Chellappan, V.; Bilic, A.; Sonar, P.; Rananaware, A.; Bhosale, S. V.; Bhosale, S. V. A Non-Fullerene Electron Acceptor Based on Fluorene and Diketopyrrolopyrrole Building Blocks for Solution-Processable Organic Solar Cells with an Impressive Open-Circuit Voltage. Phys. Chem. Chem. Phys. 2014, 16, 23837-23842.

(25) Schwenn, P. E.; Gui, K.; Nardes, A. M.; Krueger, K. B.; Lee, K. H.; Mutkins, K.; Rubinstein-Dunlop, H.; Shaw, P. E.; Kopidakis, N.; Burn, P. L.; et al. A Small Molecule Non-fullerene Electron Acceptor for Organic Solar Cells. Adv. Energy Mater. 2011, 1, 73-81.

(26) Holliday, S.; Ashraf, R. S.; Wadsworth, A.; Baran, D.; Yousaf, S. A.; Nielsen, C. B.; Tan, C.-H.; Dimitrov, S. D.; Shang, Z.; Gasparini, N. High-efficiency and Air-Stable P3HT-Based Polymer Solar Cells with a New Non-Fullerene Acceptor. Nat. Commun. 2016, 7, 11585.

(27) Bloking, J. T.; Han, X.; Higgs, A. T.; Kastrop, J. P.; Pandey, L.; Norton, J. E.; Risko, C.; Chen, C. E.; Brédas, J.-L.; McGehee, M. D.; et al. Solution-Processed Organic Solar Cells with Power Conversion Efficiencies of $2.5 \%$ using Benzothiadiazole/Imide-Based Acceptors. Chem. Mater. 2011, 23, 5484-5490.

(28) Douglas, J. D.; Chen, M. S.; Niskala, J. R.; Lee, O. P.; Yiu, A. T.; Young, E. P.; Fréchet, J. M. J. Solution-Processed, Molecular Photovoltaics that Exploit Hole Transfer from Non-Fullerene, nType Materials. Adv. Mater. 2014, 26, 4313-4319.

(29) Fang, Y.; Pandey, A. K.; Nardes, A. M.; Kopidakis, N.; Burn, P. L.; Meredith, P. A Narrow Optical Gap Small Molecule Acceptor for Organic Solar Cells. Adv. Energy Mater. 2013, 3, 54-59.

(30) Tang, C. W. Two-Layer Organic Photovoltaic Cell. Appl. Phys. Lett. 1986, 48, 183-185.

(31) Guo, X.; Bu, L.; Zhao, Y.; Xie, Z.; Geng, Y.; Wang, L. Controlled Phase Separation for Efficient Energy Conversion in Dye/Polymer Blend Bulk Heterojunction Photovoltaic Cells. Thin Solid Films 2009, $517,4654-4657$. 
(32) Li, J.; Dierschke, F.; Wu, J.; Grimsdale, A. C.; Mullen, K. Poly(2,7-carbazole) and Perylene Tetracarboxydiimide: A Promising Donor/Acceptor Pair for Polymer Solar Cells. J. Mater. Chem. 2006, $16,96-100$.

(33) Lin, Y.; Li, Y.; Zhan, X. A Solution-Processable Electron Acceptor Based on Dibenzosilole and Diketopyrrolopyrrole for Organic Solar Cells. Adv. Energy Mater. 2013, 3, 724-728.

(34) Ding, L.; Ying, H.-Z.; Zhou, Y.; Lei, T.; Pei, J. Polycyclic Imide Derivatives: Synthesis and Effective Tuning of Lowest Unoccupied Molecular Orbital Levels through Molecular Engineering. Org. Lett. 2010, 12, 5522-5525.

(35) Zhou, T.; Jia, T.; Kang, B.; Li, F.; Fahlman, M.; Wang, Y. NitrileSubstituted QA Derivatives: New Acceptor Materials for SolutionProcessable Organic Bulk Heterojunction Solar Cells. Adv. Energy Mater. 2011, 1, 431-439.

(36) Winzenberg, K. N.; Kemppinen, P.; Scholes, F. H.; Collis, G. E.; Shu, Y.; Birendra Singh, T.; Bilic, A.; Forsyth, C. M.; Watkins, S. E. Indan-1,3-dione Electron-Acceptor Small Molecules for SolutionProcessable Solar Cells: A Structure-Property Correlation. Chem. Commun. 2013, 49, 6307-6309.

(37) Wu, Y.; Bai, H.; Wang, Z.; Cheng, P.; Zhu, S.; Wang, Y.; Ma, W.; Zhan, X. A Planar Electron Acceptor for Efficient Polymer Solar Cells. Energy Environ. Sci. 2015, 8, 3215-3221.

(38) Sun, D.; Meng, D.; Cai, Y.; Fan, B.; Li, Y.; Jiang, W.; Huo, L.; Sun, Y.; Wang, Z. Non-Fullerene-Acceptor-Based Bulk-Heterojunction Organic Solar Cells with Efficiency over 7\%. J. Am. Chem. Soc. 2015, 137, 11156-11162.

(39) Holliday, S.; Ashraf, R. S.; Nielsen, C. B.; Kirkus, M.; Röhr, J. A.; Tan, C.-H.; Collado-Fregoso, E.; Knall, A.-C.; Durrant, J. R.; Nelson, J.; et al. A Rhodanine Flanked Nonfullerene Acceptor for SolutionProcessed Organic Photovoltaics. J. Am. Chem. Soc. 2015, 137, 898904.

(40) Shi, H.; Fu, W.; Shi, M.; Ling, J.; Chen, H. A SolutionProcessable Bipolar Diketopyrrolopyrrole Molecule Used as Both Electron Donor and Acceptor for Efficient Organic Solar Cells. J. Mater. Chem. A 2015, 3, 1902-1905.

(41) Amriou, S.; Wang, C.; Batsanov, A. S.; Bryce, M. R.; Perepichka, D. F.; Ortí, E.; Viruela, R.; Vidal-Gancedo, J.; Rovira, C. The Interplay of Inverted Redox Potentials and Aromaticity in the Oxidized States of New $\pi$-Electron Donors: 9-(1,3-Dithiol-2-ylidene)fluorene and 9-(1,3Dithiol-2-ylidene)thioxanthene Derivatives. Chem. - Eur. J. 2006, 12, 3389-3400.

(42) Zhao, Y.; Xu, G.; Guo, X.; Xia, Y.; Cui, C.; Zhang, M.; Song, B.; Li, Y.; Li, Y. Cooperative Assembly of an Active Layer Utilizing the Synergistic Effect of a Functional Fullerene Triad as an Acceptor for Efficient P3HT-Based PSCs. J. Mater. Chem. A 2015, 3, 17991-18000.

(43) Cowan, S. R.; Roy, A.; Heeger, A. J. Recombination in PolymerFullerene Bulk Heterojunction Solar Cells. Phys. Rev. B: Condens. Matter Mater. Phys. 2010, 82, 245207.

(44) Koster, L. J. A.; Mihailetchi, V. D.; Ramaker, R.; Blom, P. W. M. Light Intensity Dependence of Open-Circuit Voltage of Polymer:Fullerene Solar Cells. Appl. Phys. Lett. 2005, 86, 123509.

(45) Gupta, V.; Kyaw, A. K. K.; Wang, D. H.; Chand, S.; Bazan, G. C.; Heeger, A. J. Barium: An Efficient Cathode Layer for Bulkheterojunction Solar Cells. Sci. Rep. 2013, 3, 1965.

(46) Kyaw, A. K. K.; Wang, D. H.; Gupta, V.; Leong, W. L.; Ke, L.; Bazan, G. C.; Heeger, A. J. Intensity Dependence of Current-Voltage Characteristics and Recombination in High-Efficiency SolutionProcessed Small-Molecule Solar Cells. ACS Nano 2013, 7, 4569-4577.

(47) Kyaw, A. K. K.; Wang, D. H.; Gupta, V.; Zhang, J.; Chand, S.; Bazan, G. C.; Heeger, A. J. Efficient Solution-Processed SmallMolecule Solar Cells with Inverted Structure. Adv. Mater. 2013, 25, 2397-2402.

(48) Lu, L.; Xu, T.; Chen, W.; Lee, J. M.; Luo, Z.; Jung, I. H.; Park, H. I.; Kim, S. O.; Yu, L. The Role of N-Doped Multiwall Carbon Nanotubes in Achieving Highly Efficient Polymer Bulk Heterojunction Solar Cells. Nano Lett. 2013, 13, 2365-2369.

(49) Park, O. Y.; Kim, H. U.; Kim, J.-H.; Park, J. B.; Kwak, J.; Shin, W. S.; Yoon, S. C.; Hwang, D.-H. Tetrafluorene-9,9'-bifluorenylidene as a Non-Fullerene Type Electron Acceptor for P3HT-Based BulkHeterojunction Polymer Solar Cells. Sol. Energy Mater. Sol. Cells 2013, $116,275-282$. 